FACTA UNIVERSITATIS

Series: Mechanical Engineering Vol. 17, No 3, 2019, pp. 345 - 356

https://doi.org/10.22190/FUME190514042K

Original scientific paper

\title{
EXPERIMENTAL INVESTIGATION OF THE INFLUENCE OF TRAIN VELOCITY AND TRAVEL DIRECTION ON THE DYNAMIC BEHAVIOR OF STIFF COMMON CROSSINGS
}

\author{
Vitalii Kovalchuk $^{2}$, Mykola Sysyn ${ }^{1}$, Ulf Gerber ${ }^{1}$, \\ Olga Nabochenko ${ }^{2}$, Jandab Zarour ${ }^{1}$, Stefan Dehne ${ }^{1}$
}

${ }^{1}$ Institute of Railway Systems and Public Transport, TU Dresden, Germany ${ }^{2}$ Department of the rolling stock and track, Lviv branch of Dniprovsk National University of Railway Transport, Lviv, Ukraine

\begin{abstract}
Common crossing rails are subjected to a rapid deterioration of the rolling surface due to a dynamic loading of trains. The present study is devoted to an experimental study of the displacement and rail strain measurements in the common crossing. The experimental measurements were carried out for two stiff common crossings under the dynamic loading of high-speed train for the velocity range of 54$254 \mathrm{~km} / \mathrm{h}$. The results showed 2.5 times increase of the maximal displacements within the velocity range. The absence of the difference in the displacements between the trailing and the facing travel direction is explained with the relative displacement measurements between the rail and the sleeper and the different dynamic impact loading for the wing rail. The proposed model-based analysis of the absolute measurement of rail strain enables us to estimate the dynamic factor under the impact loading. The wing rail for trailing direction is almost twice as highly loaded as the frog rail for the facing direction. The maximal dynamic factor for the trailing direction shows almost no change for the velocities of more than $200 \mathrm{~km} / \mathrm{h}$.
\end{abstract}

Key Words: Railway Turnout, Common Crossing, Experimental Measurements, Dynamic Factor, Model Based Analysis

\section{INTRODUCTION}

Switches and crossings (S\&C) are significant elements of the railway network infrastructure that enable trains to change the travel direction between tracks without delays. An average $\mathrm{S} \& \mathrm{C}$ density for the European railways amounts up to 1.88 units per track kilometer [1]. German Railways (DB AG) comprise about 70000 turnouts including about

Received May 14, 2019 / Accepted October 30, 2019

Corresponding author: Mykola Sysyn

Technical University of Dresden, Hettnerstraße 3, 01069, Dresden, Germany

E-mail: mykola.sysyn@tu-dresden.de 
30000 units at heavy-duty traffic lines [2]. $90 \%$ of the turnouts on DB AG are with fixed crossing and switch angles up to 1:14. Nevertheless, S\&C are among the most problematical elements due to a high impact of traffic operation as well as enormous maintenance costs. Because of the limitation of train velocities during the travel on S\&C they are considered as a bottleneck of railway traffic in railway network. Because of high maintenance efforts and short lifecycles, S\&C are marked as "hungry assets" in [3]. The maintenance costs of S\&C amount up to $35-50 \%$ of the overall maintenance costs of track superstructure $[4,5]$. Common crossing rails are the most short-living elements of S\&C with lifecycle up to 5 times shorter than that of the ordinary track rails. The short lifecycles and the difficulties in predicting deterioration of rolling surface cause unplanned traffic interruptions that result in high operational hindrance costs [6].

The principal causes of the rapid deterioration of the common crossing rolling surface are an increased dynamic loading of the wheel, a lower contact area of frog and wing rail with wheel, high shear and wear loading, etc. A number of secondary causes influence the principal ones: wheel and rails geometrical profiles and mechanical properties, train velocity, lateral position of wheelset, trailing direction, stiffness of rail support, etc. The knowledge of the factors affecting deterioration mechanisms of the common crossing would potentially facilitate the development of technical solutions for the prolongation of the crossing lifecycle and the maintenance improvement.

Many theoretical and experimental studies appeared in the last years dealing with the dynamic interaction and deterioration mechanisms in switches and common crossings. A parametric study was carried out in [7] by means of vehicle-track simulations and it presented the impact of the train operational parameters on rail and wheel degradation. It was found that switch rail lateral loading at 1:9 type turnout is significantly influenced by the level of wheel-rail friction and less by the travel direction. The influence of vehicle speed, traction, and gauge widening and track layout is found to be small. A study of stress-strain state of stiff common crossings, optimization of its longitudinal profile and the development of rolling surface measurement system are presented in [8-10]. A detailed parametric study of the crossing geometry on the interaction influence is shown in [11]. The study indicates the longitudinal height profile of the crossing and the wheel profile as the most significant factors. A study [12] presents an experimental analysis of magnet particle images of the frog rail rolling surface during the lifecycle of the common crossing. A method for rail contact fatigue prediction using image processing and machine learning techniques is proposed. An evolution of wheel to rail contact conditions over turnout crossing is presented in the review paper [13]. Experimental studies of the development of accelerations in the frog nose of common crossing during its lifecycle are presented in [14-16]. The studies show a significant increase of the acceleration components and wheel impact position for old crossings due to the growth of rail wear. A numerical modeling of dynamic vehicle-track interaction in a railway turnout is considered in [17] by means of FEM and multibody models. The influence of long-term ballast settlements under the common crossing on the dynamic loading of train wheels is shown in the theoretical and experimental studies [18]. The present study is concentrated on the experimental investigation of the influence of train velocity and travel direction on the dynamic loading of stiff common crossings. The influence of wheel diameter difference on high-speed dynamic interaction of wheel and turnout is presented in the numerical study [19]. The influence of track stiffness on the dynamical response of railway switches and crossings is studied with the FEM simulation in [20-21]. Numerical 
simulations and influence analysis of the switch irregularities on the dynamic loadings are presented in the study [22]. The studies determined the form, parameters and basic patterns of the irregularities development in the rolling zone on switch frogs.

Almost all recent research of turnout and train interaction is based on the theoretical consideration and numerical modeling. The present paper is concentrated on the experimental investigation of turnout and train dynamic interaction. The most loaded element of turnout is considered, i.e. the common crossing. The influence of train velocity and travel direction (facing and trailing) is estimated with a conventional analysis and a model based analysis.

\section{GEOMETRICAL IRREGULARITY OF TRACK GEOMETRY ON COMMON CROSSING}

A turnout consists of 3 parts: switch panel, closure panel and crossing panel. The main elements of the crossing panel, namely of the stiff common crossing as shown in Fig. 1, right, are: frog nose rail, wing rails, guard rails, stock rails, sleeper fastenings, etc. Train vehicles are capable of traveling over a common crossing in through or diverging routes and facing or trailing directions (Fig. 1, left). The current study considers a through travel direction where the trains are allowed to move at high velocities which in its turn causes high dynamic loadings and rapid deterioration.

The reason of high dynamic loadings is a short geometrical irregularity that appears due to wheel rolling from the wing rail on the frog rail or vice versa. The explanation of the geometrical irregularity formation is presented in Fig. 2. The contact point of the wheel and the rail shifts along the wheel conicity outside while the wheel movement from the point 1 to the point 2 (Fig. 2, bottom). The wheel moves downwards owing to the radii difference. As soon as the wheel flange comes in contact with the frog rail, the contact point between the wheel and the rail jumps from point 2 on the wing rail to point 3. Afterwards the wheel rolls from point 3 to 4 of the frog rail moves upwards on the primary level. In this way the vertical structural irregularity is formed. The deterioration processes that appear in the course of turnout lifecycle, being wear or plastic deformation,

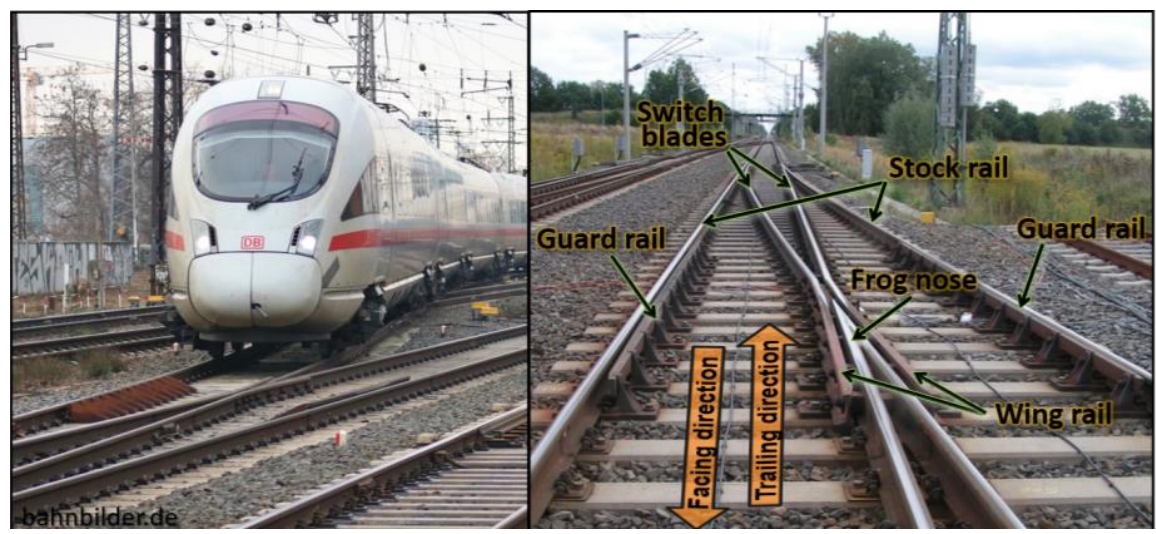

Fig. 1 ICE trailing travel on a common crossing (left) and the elements of common crossing (right) 
change the initial structural irregularity. The wear irregularity appears near the zone 2-3 of the wheel jump from the wing rail to the frog rail, where the highest dynamical loading is present. The irregularity increases the dynamic loading on the common crossing and accelerates the deterioration rate.

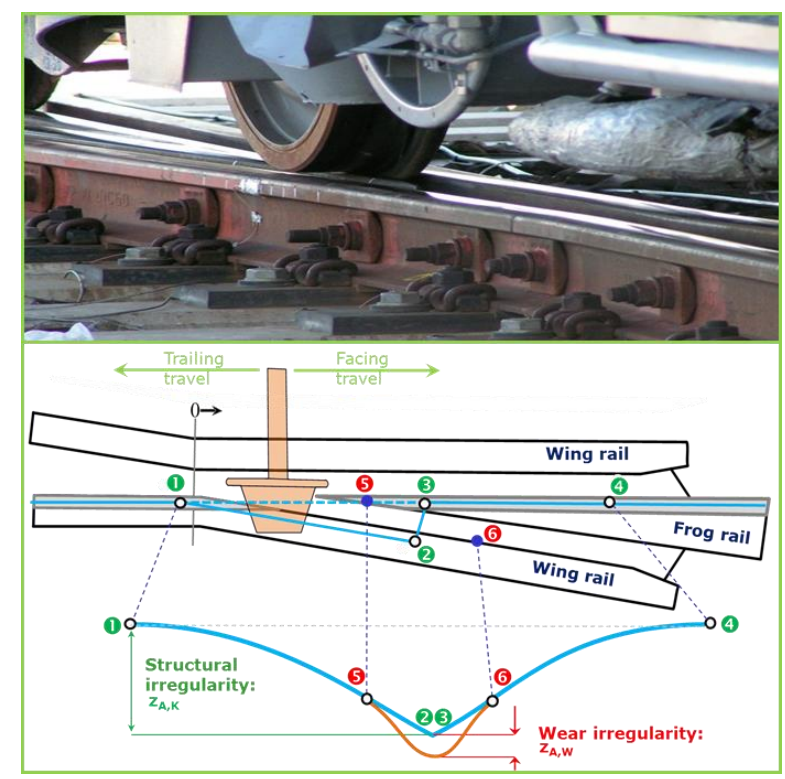

Fig. 2 Geometrical irregularity of common crossing (top: wheel travel over the frog nose, bottom: schematic description of the geometrical irregularities formation)

The form of the structural irregularity is not symmetrical; therefore, it causes different dynamic interaction in the trailing and facing directions. For an easy description of the excitation geometry function the following two demands are necessary:

1. The excitation geometry function shall be described by 2 parameters: wavelength $\lambda_{A}$ which influences the excitation frequency and wave depth $\hat{z}_{A}$ which can be considered as a measure of the wear, and,

2. The excitation geometry function must be asymmetric, as only in this case it can reproduce different behavior in the facing and trailing direction.

The evaluation of the profile measurements for the different common crossings has found the best parametrization function in the sense of a minimal deviation between calculation and measurement. The excitation geometry function is as follows:

$$
z_{A}=\frac{\hat{z}_{A}}{2} \cdot\left[1-\cos \left(2 \pi \cdot\left(\frac{x_{A}}{\lambda_{A}}\right)^{2}\right)\right],
$$

where $z_{A}, x_{A}$ - the local relative function and coordinate point of the excitation geometry.

The function parameters are chosen according to the following assumptions:

1. The wavelength is assumed for all points with $\lambda_{A}=3000 \mathrm{~mm}$ (this value also corresponds very well to the theoretical and measured wavelength at similar points). 
2. A change in wave depth $\hat{z}_{A}$ corresponds to an extension / compression of the excitation geometry function.

3. The magnitude of the asymmetry is set by the coefficient within the cosine argument (in case the coefficient has the value 1, the excitation geometry function is symmetric).

Fig. 3 shows the normalized excitation function and its variation with wave depth $\hat{z}_{A}$.
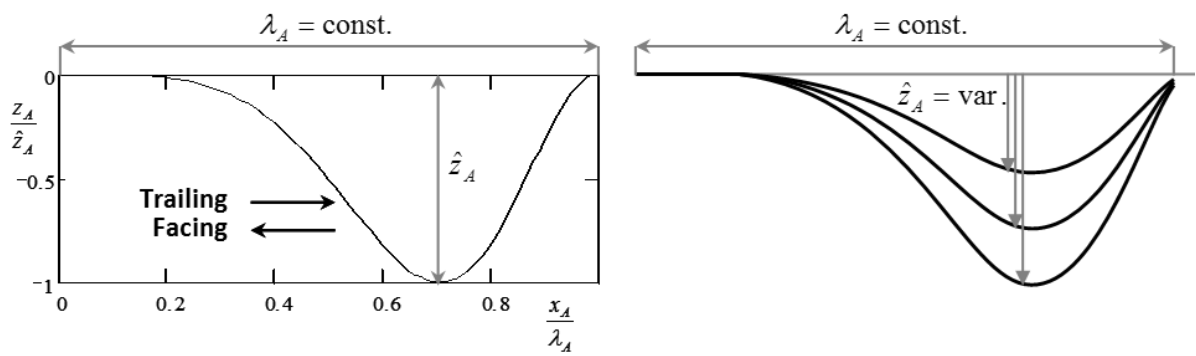

Fig. 3 The excitation geometry function

\section{EXPERIMENTAL MEASUREMENTS OF TRAIN AND CROSSING INTERACTION}

The experimental measurements were carried out for 2 turnouts S1 and S2 of type EW60-500-1:12 with assembled stiff crossings. The train of type BR401 used the test dynamic loadings with velocities from 54 to $254 \mathrm{~km} / \mathrm{h}$ in facing and trailing directions of the through routes. The measurement equipment consisted of the strain gauge sensors and inductive displacement sensors. The sensor layout is demonstrated in Fig. 4.

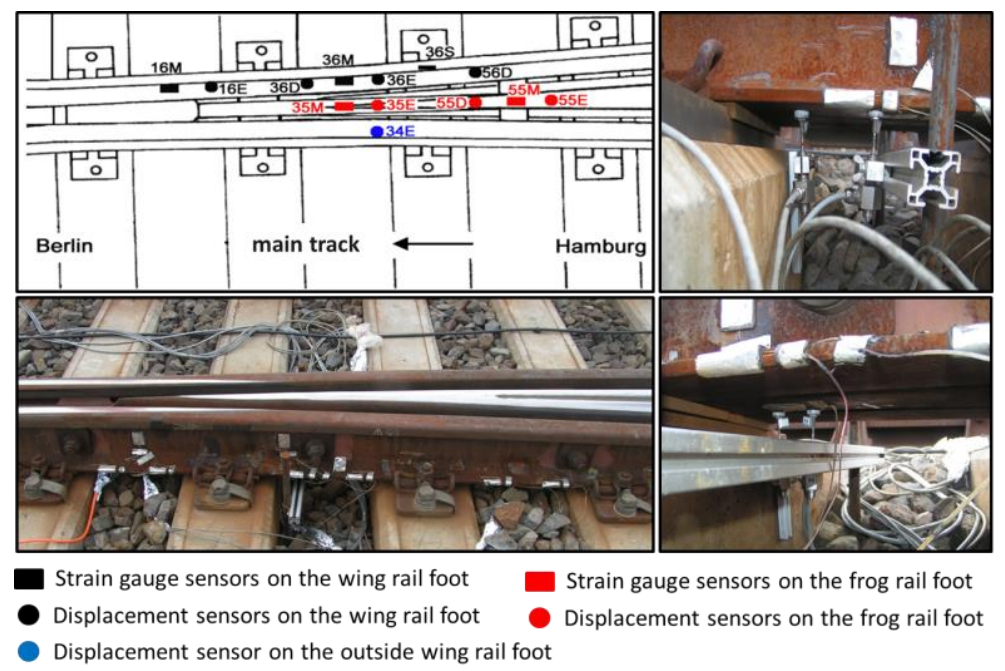

Fig. 4 Sensor layout on the common crossing 1:12 (left top: schematic of the crossing, left down: sensors $16 \mathrm{M}, 16 \mathrm{E}, 36 \mathrm{D}, 36 \mathrm{M}, 36 \mathrm{E}, 36 \mathrm{~S}, 56 \mathrm{D}$, right: sensors layout for the differential displacement measurement) 
Altogether 8 displacement sensors were installed on the sleepers to measure the differential wheel to sleeper displacements: 4 sensors are installed under the wing rail, 3 under the frog rail and one - under the opposite unloaded wing rail. Three strain gauge sensors were installed on the wing rail foot and two on the frog rail.

The most loaded areas of common crossing correspond to sensors $36 \mathrm{D}, 35 \mathrm{M}$ under the wing rail and 55E, 55M under the frog rail. The examples of the displacement and strain signal records within the same $\mathrm{x}$-coordinate scale for the middle and high velocities are shown in Figs. 5 and 6. Both the strains and the displacement signals demonstrate the impact similar interaction due to the wheel jump on the wing or frog rail. Outside of the impact zones the slow changes of strain and displacement owing to the track longitudinal deformation distribution can be observed that is the quasi-static deformation.

The quasi-static component of deformation for the wing rail is higher than for the frog rail that could be explained with much higher bending stiffness in the frog zone. Different to the wing rail, the strains in the frog rail (Fig. 6, bottom) have a noticeable negative impact zone that could be only explained with the sudden loss of the contact to the wheel during its jump from the wing rail and the negative displacement frog rail.

The increase of velocity causes a corresponding increase of displacement and strains for the wing rail and the frog rail. However, it is difficult to estimate the interrelations with the operational conditions only from Figs. 5 and 6. To study the statistical influences of train velocity and the travel direction, Fig. 7 is built that shows the displacements and strains for the facing and trailing travel directions. The increase of velocity causes a clear increase of displacement for all inductive sensors. The average displacement for all sensors is somewhat higher for the facing direction than for the trailing one. However, the maximal displacements of wing rail and frog rail for high velocities are similar.
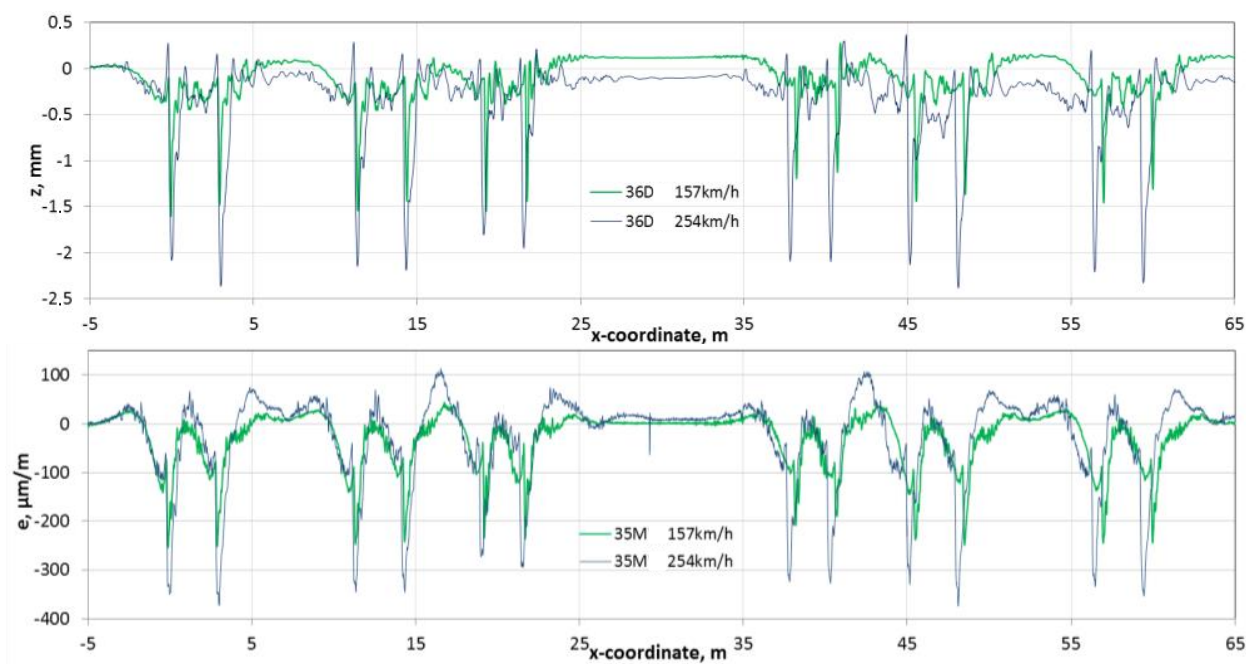

Fig. 5 Wing rail to sleeper vertical displacement (top) and strain in wing rail foot (bottom) 

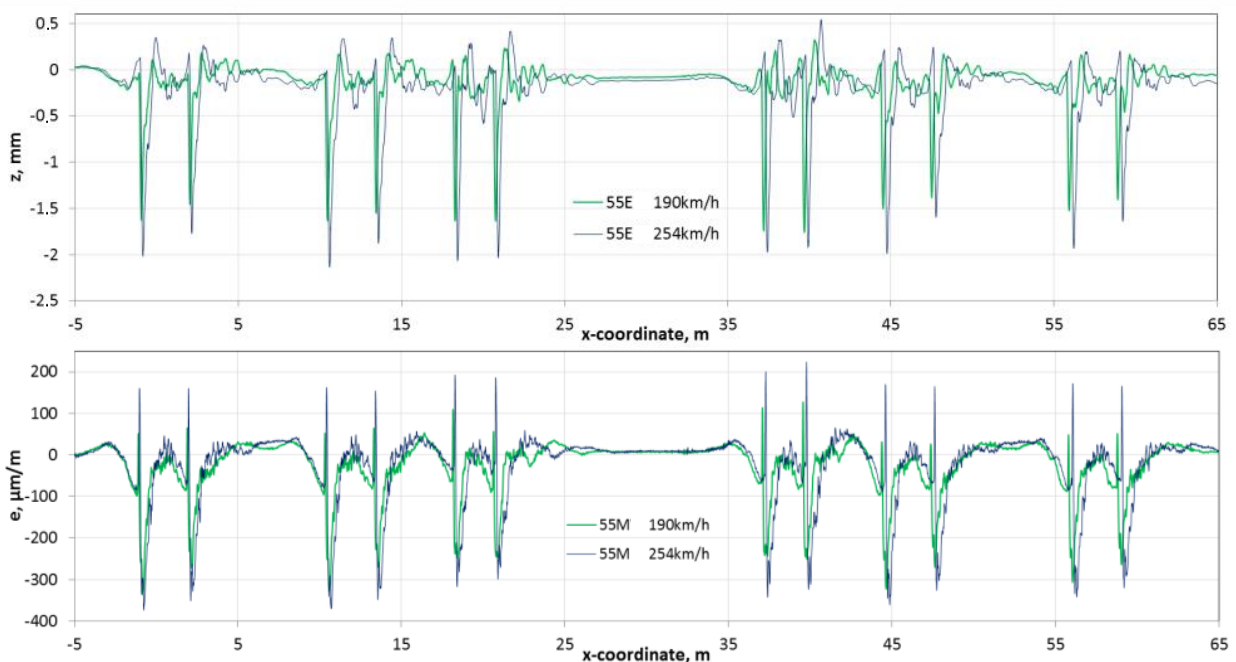

Fig. 6 Frog rail to sleeper vertical displacement (top) and strain in frog rail foot (bottom)

The analysis of strains shows a quite different relation to velocity. The strain gauge sensors $16 \mathrm{M}$ for facing and $55 \mathrm{M}$ for trailing show a significant decrease of strain with a velocity increase, while other sensors show the growth of strain. This effect can be clearly explained with the topological analysis of sensor location. These sensors are the farthest from the impact zone and record the quasi-statical strain that does not depend on the impact. The behavior of the sensors signals depending on velocity could be explained if the inertial effect of the subgrade is taken into account. The displacement sensors cannot take into account the effect due to the differential displacement measurements between the rail and sleeper. The average growth of displacements is 2.5 times for the displacements and 1.4 times for the strains within the velocity variation from 50 to $250 \mathrm{~km} / \mathrm{h}$.

The analysis of strains and displacement, their mean values and variations (Fig. 7), gives some relation to velocity but cannot indicate the difference between the trailing and the facing directions despite of quite different excitation geometries for both cases (Fig. 3). The wheel attack angle for the trailing direction is almost 2 times higher and this should evidently cause a higher dynamic loading of stiff common crossings. Nevertheless, the performed analysis of the maximal displacements and strains cannot validate this statement and, therefore, the maximal values analysis cannot be considered as a plausible way for the dynamic loading estimation. The reasons of the behavior could be found in the dynamic interaction. The travel in the trailing direction produces the impact loading and in the facing - a relatively smooth interaction. According to the study [23] where the dynamic modeling of wheel and crossing is carried out, the dynamic oscillation of the rail support in the case of impact loading produces much higher loading on the sleepers that for the smooth loading. Due to the increase of the dynamic stiffness in the rail fastenings, the measured differential displacements for the trailing direction are lower than for the facing direction and, therefore, cannot be used for the dynamic factor estimation. The measured strains do not have this disadvantage due to absolute measurements. However, a lot of factors influence the strain measurements, like changing bending stiffness, the dynamic influence of subgrade, etc. To exclude the factors the model based data analysis is necessary. 

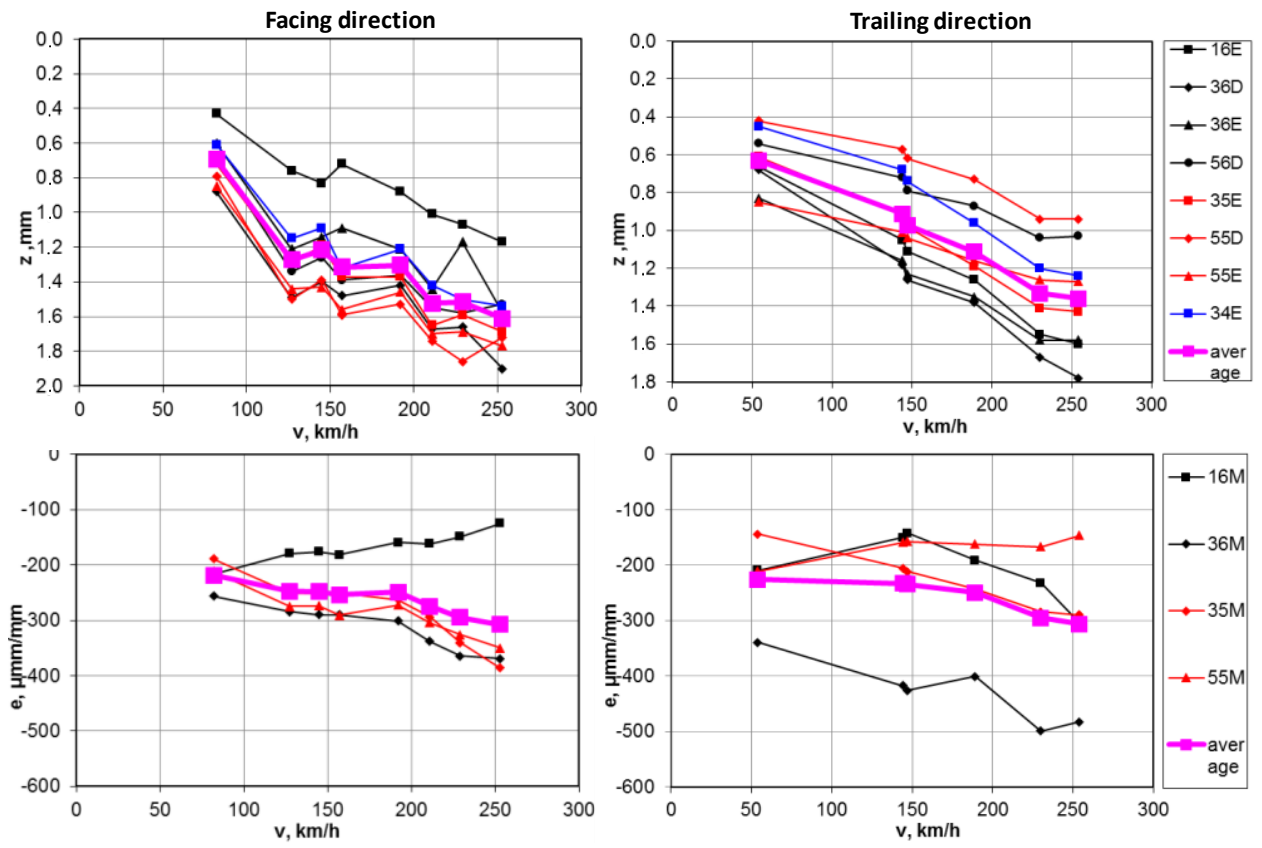

Fig. 7 Rail to sleeper vertical displacements (top) and strain in frog rail foot (bottom) depending on train velocity and travel direction

\section{Model-BASED ANALYSIS OF THE MEASUREMENTS}

The basis for the calculation of the dynamic factor with model-based approach is the relation between the measured and the calculated values with the model of the beam on the elastic foundation. The values are the displacement and strain distribution along the rail. According to the analytical calculation method $[23,24]$, displacement $z_{0}(x)$ and strain distribution $\varepsilon_{0}(x)$ along the rail are proportional to influence functions $\eta(x)$ and $\mu(x)$ :

$$
\begin{aligned}
& \varepsilon_{0}(x)=K_{\mu} \cdot F_{0} \cdot \mu(x), \\
& z_{0}(x)=K_{\eta} \cdot F_{0} \cdot \eta(x),
\end{aligned}
$$

where $K_{\mu}$ and $K_{\eta}$ - the proportionality factors that depend on the unknown elastic properties of the track and must be determined experimentally; $F_{0}-$ static wheel force.

Moment influence function $\mu(x)$ and displacement influence function $\eta(x)$ result from the superposition of the $n$ wheels of a vehicle with their position $x_{i}$ relative to the position of the measurement point [25]:

$$
\mu(x)=\sum_{i=1}^{n} e^{-\left|\frac{x-x_{i}}{L}\right|} \cdot\left[\cos \left|\frac{x-x_{i}}{L}\right|-\sin \left|\frac{x-x_{i}}{L}\right|\right],
$$




$$
\eta(x)=\sum_{i=1}^{n} e^{-\left|\frac{x-x_{i}}{L}\right|} \cdot\left[\cos \left|\frac{x-x_{i}}{L}\right|+\sin \left|\frac{x-x_{i}}{L}\right|\right],
$$

where $L$ - characteristic length, that describes the properties of rail support and rail bending.

The characteristic length is determined with the following formula:

$$
L=\sqrt[4]{\frac{4 E I \cdot a}{c_{z}}}
$$

where $E I$ - bending stiffness of rail, $a$ - distance between sleeper axes, $c_{z}$ - stiffness of rail support.

Fig. 8 depicts the explanation of influence functions $\mu(x / L)$ and $\eta(x / L)$ for the relative coordinate and their relation to the point loading.
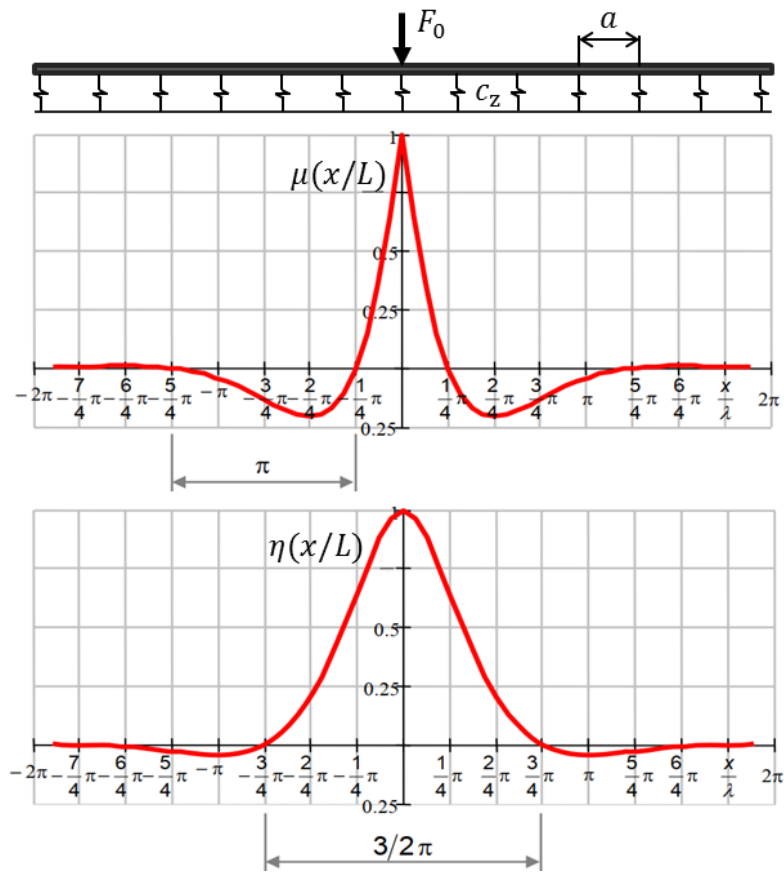

Fig. 8 The beam on elastic supports (top) and influence functions $\mu(x / L)$ and $\eta(x / L)$ (middle, bottom)

The dynamic factor is defined as the ratio between the measured and the model values of strain or displacements. The measured strains take into account the absolute track deformations contrary to the measured differential displacements that do not take into account the subgrade dynamic deformations. Therefore, only the strains are used for further analysis of the dynamic factor. It is determined by the following relation: 


$$
k_{D}=\frac{\varepsilon(x)}{\varepsilon_{0}(x)} .
$$

While the vehicle parameters are included in the technical data sheets of the vehicles, the track parameters are fitted by adapting quasistatic strain curve $\varepsilon_{0}(x)$ to measured strain curve $\varepsilon(x)$ in the non-dynamically affected areas as shown in Fig. 9 (top). The blue line corresponds to measured strain $\varepsilon(x)$, the red one corresponds to calculated strain curve $\varepsilon_{0}(x)$. The first dynamic oscillation is marked with the red and yellow markers. Fig. 9 (bottom) demonstrates the calculation of dynamic factors for each wheel axle. Maximal dynamic factor $k_{D \max }$ that corresponds to the yellow marker is taken into account for further analysis.

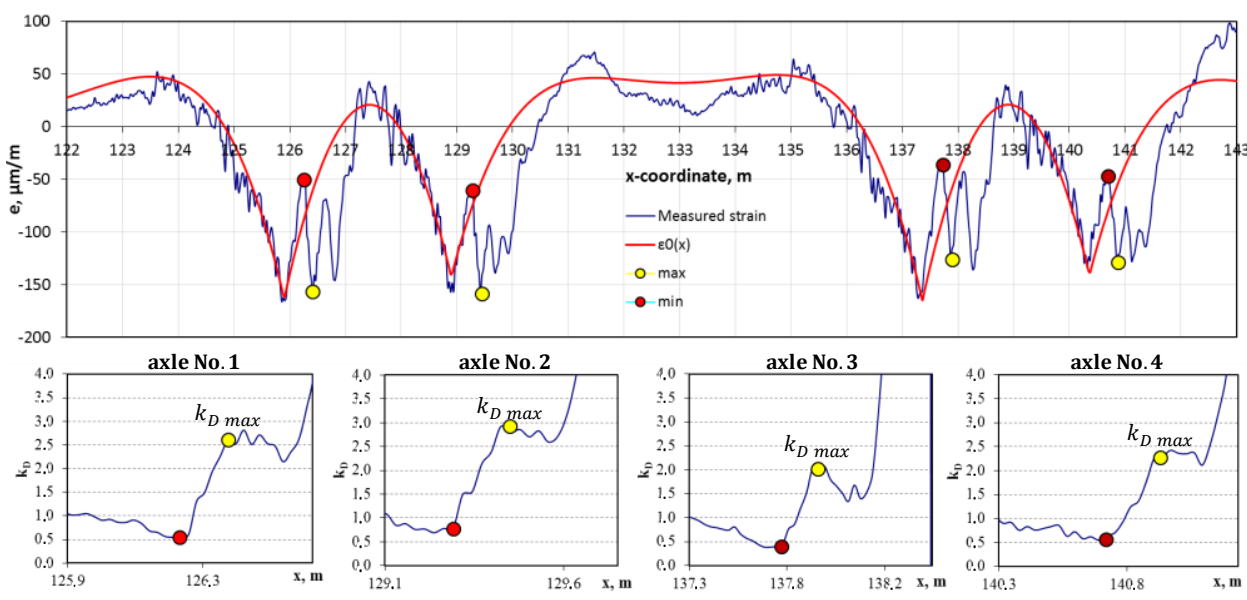

Fig. 9 Determination of the experimental dynamics factor from strain measurements

The results of maximal values of dynamic factor $k_{\text {Dmax }}$ for two turnouts $\mathrm{S} 1$ and $\mathrm{S} 2$, train velocity range up to $254 \mathrm{~km} / \mathrm{h}$ and facing/trailing travel direction is presented in Fig. 10. The calculated set of dynamic factors is appended with prior known value 1 for the zero velocity. The diagram shows up to a twice higher dynamic factor for the trailing travel than for the facing one within the velocity range $100-160 \mathrm{~km} / \mathrm{h}$. However, the dynamic factor for the trailing travel after $200 \mathrm{~km} / \mathrm{h}$ has almost no growth. The outlier points for the trailing travel of the turnout S2 can be explained with the different rail wear that makes the excitation smoother. The maximal dynamic factor for the trailing travel reaches 3.6 and for the facing travel is about 2.2. The comparison of the dynamic factor results for the model based analysis and the maximal measured value analysis (Fig. 7) shows similar values for the displacement in facing direction. The factor by the maximal values for the displacement in the trailing direction is much lower than the determined with the model-based estimation due to the influence of impact loading on the differential displacement between rail and sleeper. 


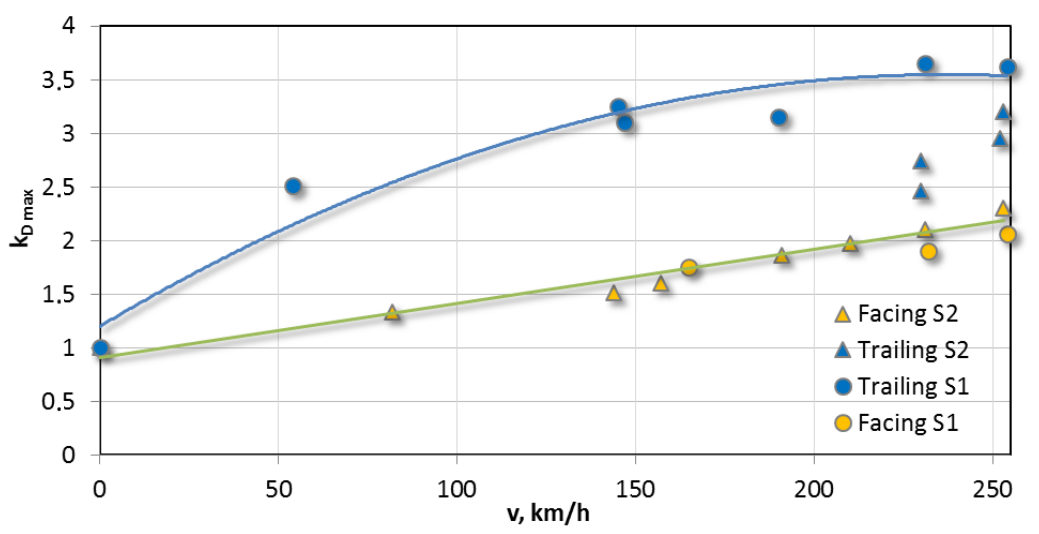

Fig. 10 Dynamics factor vs. train velocity for facing and trailing directions

\section{CONCLUSIONS}

The study presents the results of experimental measurements analysis of the influence of high speeds and the travel direction on the common crossing loading. The analysis of the maximal values of differential displacement demonstrates their growth up to 2.5 times. The growth appears in all measurement points within the velocity range between 54 to $254 \mathrm{~km} / \mathrm{h}$, both for facing and trailing travel directions. The measured maximal strains are not as explicit as the displacement results. The strain gauge sensors, which are opposite to the impact zones on the wing and frog rail, show a significant decrease of the maximal values with increasing velocities of trains. The main difference between the displacement and the strain measurements is that the measured displacements do not take into account the subgrade displacements. Additionally, the increase of dynamic stiffness of rail fastenings between sleeper and rail causes the dynamic displacements to be lower for trailing direction than for the facing one despite of a higher dynamic loading in trailing direction. The rail strain measurements are absolute, contrary to the differential displacement measurement that are relative. However, the ambiguity of strain measurements makes it impossible for use in a simple analysis of maximal values due to the influence of many unknown factors. The proposed model based analysis allows for excluding the factors. Unlike the maximal value analysis, the model based analysis utilizes more efficiently available information provided by the measurements. The results of the model based analysis show a clear difference in dynamic loading for trailing and facing travel. The wing rail for trailing direction is almost twice as highly loaded as the frog rail for the facing direction. The maximal dynamic factor for the trailing direction shows almost no change for the velocities of more than $200 \mathrm{~km} / \mathrm{h}$.

\section{REFERENCES}

1. DESTination RAIL, 2018, Decision support tool for rail infrastructure managers, Deliverable 1.3 Report on monitoring Switches and Crossings, EU project H2020-MG2014-2015, $65 \mathrm{p}$.

2. Zoll, A., 2016, Werkstoffauswahl für Weichenhetzstücke durch Prüfstandversuche (Material selection for point frog points with test bench tests), PhD Thesis, TU Berlin, Shaker Verlag Aachen, $172 \mathrm{p}$. 
3. Pfeil, H., Broadley, J.R., 1991, Turnouts, 'The hungry asset', 6th Conference on Railway Engineering: Demand Management of Assets, Adelaide, Australia, 91(18), pp. 176-184.

4. Lay, E., Rensing, R., 2013, Weichen (Railway turnouts), In Fendrich, L., Fengler, W., (Eds.), Handbuch Eisenbahninfrastruktur (Field manual Railway Infrastructure), Vol. 2, pp. 239-306, Springer-Verlag Berlin Heidelberg.

5. Zwanenburg, W.J., 2009, Modelling degradation processes of switches \& crossings for maintenance \& renewal planning on the Swiss Railway Network, PhD Thesis, Ecole Polytechnique Federale de Lausanne, Switzerland.

6. Wan, C., Markine, V.L., Shevtsov, I.Y., 2014, Analysis of train/turnout vertical interaction using a fast numerical model and validation of that model, Proc Instn Mech Engrs Part F: Journal of Rail and Rapid Transit, 228(7), pp. 730-743.

7. Hiensch, E.J.M., Burgelman, N., 2017, Switch Panel wear loading-a parametric study regarding governing train operational factors, Vehicle System Dynamics, 55(9), pp. 1384-1404.

8. Kovalchuk, V., Bolzhelarskyi, Y., Parneta, B., Pentsak, A., Petrenko, O., Mudryy, I., 2017, Evaluation of the stressed-strained state of crossings of the 1/11 type turnouts by the finite element method, EasternEuropean Journal of Enterprise Technologies, 4(7-88), pp. 10-16.

9. Kovalchuk, V., Sysyn, M., Sobolevska, J., Nabochenko, O., Parneta, B. and Pentsak, A., 2018, Theoretical study into efficiency of the improved longitudinal profile of frogs at railroad switches, Eastern-European Journal of Enterprise Technologies, 94(4), pp. 27-36.

10. Kovalchuk, V., Sysyn, M., Hnativ, Y., Bal, O., Parneta, B., Pentsak, A., 2018, Development of a promising system for diagnosing the frogs of railroad switches using the transverse profile measurement method, Eastern European Journal of Enterprise Technologies, 92(2), pp. 33-42.

11. Wan, C., Markine, V.L., 2015, Parametric study of wheel transitions at railway crossings, Vehicle System Dynamics, 53(12), pp. 1876-1901.

12. Sysyn, M., Gerber, U., Nabochenko, O., Gruen, D., Kluge, F., 2019, Prediction of rail contact fatigue on crossings using image processing and machine learning methods, Urban Rail Transit, 5(2), pp. 123-132.

13. Hamarat, M.Z., Kaewunruen, S., Papaelias, M., 2019, Contact conditions over turnout crossing noses, IOP Conference Series: Materials Science and Engineering, 471(6), 062027.

14. Sysyn, M., Gerber, U., Nabochenko, O., Kovalchuk, V., 2019, Common crossing fault prediction with track based inertial measurements: statistical vs mechanical approach, Pollack Periodica, 14(2), pp. 15-26.

15. Sysyn, M., Nabochenko, O., Kluge F., Kovalchuk, V., Pentsak, A., 2019, Common crossing structural health analysis with track-side monitoring, Communications - Scientific Letters of the University of Zilina, 21(3), pp. 79-86

16. Sysyn, M., Gerber, U., Nabochenko, O., Li, Y., Kovalchuk, V., 2019, Indicators for common crossing structural health monitoring with track-side inertial measurements. Acta Polytechnica, 2019, 59(2), pp. 170-181.

17. Blanco-Saura, A.E., Velarte-González, J.L., Ribes-Llario, F., Real-Herráiz, J.I., 2017, Study of the dynamic vehicle-track interaction in a railway turnout, Multibody System Dynamics, 43(1), pp. 21-36.

18. Sysyn, M., Gerber, U., Gruen, D., Nabochenko, O., Kovalchuk, V., 2019, Modelling and vehicle based measurements of ballast settlements under the common crossing, European Transport / Transporti Europei - International Journal of Transport Economics, Engineering and Law, 71, pp. 1-25.

19. Chen, R., Chen, J.-Y., Wang, P., Xu, J.-M., Xiao, J.-L., 2017, Numerical investigation on wheel-turnout rail dynamic interaction excited by wheel diameter difference in high-speed railway, Journal of Zhejiang University: Science A, 18(8), pp. 660-676.

20. Salajka, V., Smolka, M., Plasek, O., Kala, J., 2016, Numerical analysis of dynamic response in railway switches and crossings. Applied System Innovation - Proceedings of the International Conference on Applied System Innovation, ICASI 2015, pp. 1163-1168.

21. Salajka, V., Smolka, M., Kala, J., Plášek, O., 2017, Dynamical response of railway switches and crossings, MATEC Web of Conferences 107, 00018.

22. Boiko, V., Molchanov, V., Tverdomed, V., Oliinyk, O., 2018, Analysis of vertical irregularities and dynamic forces on the switch frogs of the underground railway, MATEC Web of Conferences, 230, 01001.

23. Fengler, W., Gerber, U., 2007, Belastung von Weichen mit starrer Herzstïckspitze (Loading of Turnouts with stiff Crossings), ZEVrail Glasers Annalen, 5, pp. 202-214.

24. Heppe, A., 2010, Ein Beitrag zur Modellierung und messtechnischen Bestimmung des Langzeitverhaltens von starren Weichenherzstïcken (A contribution to the modeling and metrological determination of the long-term behaviour of rigid common crossings), $\mathrm{PhD}$ Thesis, TU Dresden, $154 \mathrm{pp}$.

25. Führer, G., 1978, Oberbauberechnung, VEB, Verlag für Verkehrswesen, Berlin. 151 p. 